\title{
Prevalence and associated factors of gestational diabetes mellitus among rural pregnant women in southern Tanzania
}

\author{
Fabian P. Mghanga ${ }^{1}$, Elia A. Maduhu ${ }^{1}$ and Helmut A. Nyawale ${ }^{2}$ \\ Ghana Med J 2020; 54(2): 82-87 DOI: http://dx.doi.org/10.4314/gmj.v54i2.5 \\ ${ }^{1}$ Department of Internal Medicine, Faculty of Medicine, Archbishop James University College, Songea, \\ Tanzania \\ ${ }^{2}$ Department of Community Medicine, Faculty of Medicine, Archbishop James University College, Songea, \\ Tanzania
}

Corresponding author: Fabian P. Mghanga

E-mail: fpmghanga@ajuco.ac.tz

\author{
Conflict of interest: None declared
}

\section{SUMMARY}

Introduction: Gestational diabetes mellitus (GDM) is a potential risk factor for both maternal and foetal complications during pregnancy. This study aimed to determine the prevalence and factors associated with GDM among pregnant women in Southern Tanzania.

Methods: A cross-sectional study was conducted among 612 randomly selected pregnant women attending routine antenatal clinics in Southern Tanzania from September to October 2017. Detailed medical and gynaecological history was taken using pre-tested questionnaires. Blood samples were collected for fasting and oral glucose tolerance tests. We diagnosed GDM using the World Health Organization 2013 diagnostic criteria for diabetes mellitus. We performed statistical analysis using SPSS v24.0. Possible associations and statistical significance were measured using odds ratio at $95 \%$ confidence interval, and $p$-values of $<0.05$ were considered statistically significant.

Results: The mean age and standard deviation of the study subjects was $24.5 \pm 6.9$ years. The prevalence of GDM was $4.3 \%$. GDM was significantly associated with: being overweight or obese $(\mathrm{p}<0.001)$, past history of pre-term delivery $(p<0.001)$, past history of stillbirths $(p<0.001)$, history of macrosmia $(p<0.001)$, alcohol consumption $(\mathrm{p}=0.001)$, and having a first degree relative with diabetes mellitus $(p<0.001)$.

Conclusion: Prevalence of Gestational Diabetes Mellitus is low in this study setting. We recommend close attention to at risk women to prevent development of GDM.

Keywords: Diabetes mellitus; Gestational diabetes mellitus; risk factors.

Funding: None declared

\section{INTRODUCTION}

According to the 2013 World Health Organization (WHO) diagnostic criteria, gestational diabetes mellitus is defined as any degree of glucose intolerance leading to hyperglycaemia of different grades with onset or first recognition during pregnancy. ${ }^{1}$ Gestational diabetes mellitus more commonly manifest during the third trimester although symptoms may start to be noticed as early as the end of the second trimester. In majority of cases, gestational diabetes mellitus will resolve after delivery, however the affected women are still at higher risks of developing type 2 Diabetes Mellitus later in life. ${ }^{2,3}$ Gestational diabetes mellitus may lead to multiple maternal complications including antepartum haemorrhage, hypertensive disorders during pregnancy and risk of future diabetes mellitus; and foetal and neonatal complications such as still birth, dystocia, spontaneous abortion, macrosomia, prematurity and respiratory distress syndrome and the risk of developing neonatal diabetes. ${ }^{4,5}$ Factors such as family history of diabetes, age above 25 years, having a body-mass-index of more than 25 , weight gain during pregnancy, poor dietary habits during pregnancy, cigarette smoking and sedentary life style have been implicated with the development of gestational diabetes mellitus. ${ }^{6-9}$

Gestational diabetes mellitus affects about 5.9\%-14.0\% of pregnant women in low and middle-income countries. ${ }^{10}$ Between $3 \%$ and $19 \%$ of pregnancies in the high-income countries ${ }^{11-14}$ and $0 \%$ and $9.1 \%$ in low and middle-income African countries are affected by gestational diabetes ${ }^{15-21}$ while one meta-analysis involving 22 studies reported a gestational diabetes 
mellitus prevalence of 2-6\% in sub-Saharan Africa. ${ }^{22}$ This notable discrepancy is largely due to the differences in the diagnostic tests and criteria used.

In Tanzania, using the 1999 and 2013 diagnostic criteria, studies in the eastern ${ }^{23}$ and northern eastern regions ${ }^{24}$ reported prevalence rates of $8.4 \%$ and $19.5 \%$, respectively; and another study conducted three decades earlier using the 1985 diagnostic criteria, reported zero prevalence of GDM and impaired glucose tolerance in pregnant women. ${ }^{17}$ The trend shows an increase in the prevalence of GDM with probable increase in both maternal and foetal complications. The study site is one of the areas within the country experiencing an increasing burden of risk factors for non-communicable diseases. However, no study on GDM has been done in this study area. Because of this gap and the increased burden of non-communicable diseases in the study area, we aimed to determine the prevalence and associated factors of gestational diabetes mellitus among a cohort of pregnant women in Ruvuma, Southern Tanzania.

\section{METHODS}

\section{Study design and setting}

This was a hospital-based cross-sectional study done between September and October 2017 at Songea Regional Referral Hospital located in Songea Municipal, Ruvuma region in the southern highlands of Tanzania. The hospital has more than 320 beds with over 450 outpatients visits daily and serves as a secondary level referral facility. The region is about $716.4 \mathrm{~km}$ from the Dodoma, country's capital city, and has an estimated population of 1.377 million people.

\section{Sample size and sampling technique}

All pregnant women aged 14 years and above with gestational age of 20 weeks and above and of any parity, and who consented were included in the study. Women who were known patients of diabetes mellitus, on antiepileptics, or who had chronic illness were excluded from the study. The sample size was calculated based on the recent prevalence rate of $19.5 \%$ reported in northern Tanzania, ${ }^{4}$ with a $95 \%$ confidence interval and a $\pm 5 \%$ degree of precision, non-response rate (10\%) and design effect of 2 .

\section{Data collection and clinical assessment Socio-demographic characteristics}

Data were collected using a structured questionnaire that included variables on socio-demographic characteristics, medical and obstetrics history. Socio-demographic information collected included women' age, residence, marital status, employment status, economic status, education level, parity, gestation age, smoking status, family history of diabetes mellitus among first degree-relatives, and alcohol use.

\section{Clinical assessment and anthropometrics}

All participating women underwent physical examination and biochemical investigations. All examinations were done by the investigators assisted by two medical doctors and a trained nurse. The body mass indices (BMI) were calculated as weight (in kilograms) divided by the square of height (in meters). Because of the nature of the study, the pre-pregnancy BMI could not be measured. We therefore measured the pregnancy BMI or used the recorded BMI when the woman was at 20 weeks of gestation. Participants were classified into the WHO categories for underweight $\left(<18.5 \mathrm{~kg} / \mathrm{m}^{2}\right)$, normal weight $(\geq$ $\left.18.5-24.9 \mathrm{~kg} / \mathrm{m}^{2}\right)$, overweight $\left(\geq 25-29.9 \mathrm{~kg} / \mathrm{m}^{2}\right)$ and obese $\left(\geq 30 \mathrm{~kg} / \mathrm{m}^{2}\right) .{ }^{25}$

\section{Assessment of gestational diabetes mellitus}

Cases were identified using the Oral Glucose Tolerance Test (OGTT) which is the gold standard for the diagnosis of GDM. Following an overnight 8-hour fast, a venepuncture was performed for fasting blood glucose. Women who had fasting plasma glucose of $<7.0 \mathrm{mmol} / \mathrm{L}$ were given a glucose load comprised 75 g glucose monohydrate dissolved in $250 \mathrm{ml}$ water. Venous blood samples for plasma glucose levels were taken at 1 and 2 hours post-glucose load. Measurement of blood glucose was done using a glucose oxidase method (Lab Kit, Madrid, Spain) using a spectrophotometer RT-9200 semiautomatic chemistry analyzer. The coefficient of variation of the assay was $2.3 \%$. Based on the 2013 WHO diagnostic criteria, ${ }^{26}$ a pregnant women with gestational diabetes mellitus was confirmed if the level of fasting plasma glucose was $5.1-6.9 \mathrm{mmol} / \mathrm{L}, 1 \mathrm{~h}-\mathrm{h}$ plasma glucose $\geq 10.0 \mathrm{mmol} / \mathrm{L}$, and/or 2-h plasma glucose $8.5-11.0$ $\mathrm{mmol} / \mathrm{L}$, while diabetes in pregnancy was diagnosed if fasting plasma glucose was $\geq 7.0 \mathrm{mmol} / \mathrm{L}$ or the 2 hours plasma glucose was $>11.1 \mathrm{mmol} / \mathrm{L}$.

\section{Statistical analysis}

All analyses were performed using IBM's SPSS Statistical Software for Windows (IBM SPSS Version 24, Chicago, Illinois, USA). Socio-demographic characteristics were evaluated using proportions (\%) for categorical variables and means ( \pm standard deviations) for continuous variables. Adjusting for covariates of interest, we used bivariate logistic regression analysis to calculate odds ratios and $95 \%$ confidence intervals $(95 \% \mathrm{CI})$ to estimate associations of variables and GDM. All reported $p$-values are deemed statistically significant at $<0.05$.

\section{Ethical consideration}

Ethical clearance was obtained from the Institutional Ethical Committee (Ref. no. IREC01-2017/0013), Archbishop James University College, Songea and an approval to conduct the study was granted by the office of the Regional Medical Officer. 
Purpose of the study was explained to participating women and informed written consent obtained.

\section{RESULTS}

A total of 612 pregnant women were included in the analysis. The mean \pm standard deviation age of study participants was $24.5 \pm 6.9$ years (range $15-48$ ) and the mean \pm standard deviation gestational age of all study

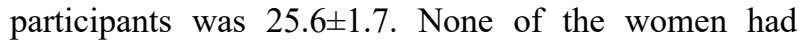
known history of diabetes mellitus or previous history of gestational diabetes mellitus; however, forty-eight (7.9\%) women had relatives with first degree family history of diabetes mellitus. The mean body mass-index was $20.5 \pm 0.4 \mathrm{~kg} / \mathrm{m}^{2}$ and the mean systolic and diastolic blood pressure was $110.3 \pm 12.4$ and $65 \pm 11.8 \mathrm{mmHg}$, respectively. Forty-five $(7.4 \%)$ mothers had a previous history of spontaneous abortion (Table 1).

Table 1 Characteristics of the study participants

\begin{tabular}{|c|c|}
\hline Variable & Mean \pm SD $/ \mathbf{n}(\%)$ \\
\hline Age (years), mean & $28.5 \pm 6.9$ \\
\hline Mean fasting plasma glucose & $3.9 \pm 0.5$ \\
\hline Mean 2-hour glucose level & $5.5 \pm 1.2$ \\
\hline Gestational age & $25.6 \pm 1.7$ \\
\hline Height (cm) & $152.6 \pm 1.8$ \\
\hline Weight (kg) & $47.7 \pm 0.7$ \\
\hline BMI $\left(\mathrm{kg} / \mathrm{m}^{2}\right)$ & $20.5 \pm 0.4$ \\
\hline Systolic blood pressure (mmHg) & $110.3 \pm 12.4$ \\
\hline Diastolic blood pressure (mmHg) & $65 \pm 11.8$ \\
\hline \multicolumn{2}{|l|}{ Potential risk factors for GDM } \\
\hline Advanced maternal age, $\geq 35$ years & $158(25.8)$ \\
\hline Known history of diabetes mellitus & $0(0.0)$ \\
\hline History of pre-term delivery & $30(4.9)$ \\
\hline History of spontaneous abortion & $125(20.4)$ \\
\hline History of stillbirths & $32(5.2)$ \\
\hline History of macrosomia & $45(7.4)$ \\
\hline History of alcohol consumption & $73(12.0)$ \\
\hline Previous history of GDM & $0(0.0)$ \\
\hline $\begin{array}{l}\text { First degree relative with diabetes } \\
\text { mellitus }\end{array}$ & $48(7.9)$ \\
\hline History of smoking & $5(0.8)$ \\
\hline \multicolumn{2}{|l|}{ Gravidity } \\
\hline First & $154(25.2)$ \\
\hline Second & $215(35.1)$ \\
\hline Third or more & $243(39.7)$ \\
\hline
\end{tabular}

Abbreviations: SD, Standard deviation; BMI, Body mass-index; GDM, Gestational diabetes mellitus

The mean fasting blood glucose and the mean 2-h postprandial glucose was $3.9 \pm 0.5$ and $5.5 \pm 1.2 \mathrm{mmol} / \mathrm{L}$, respectively. Five women had fasting plasma glucose levels $\geq 7.0 \mathrm{mmol} / \mathrm{L}$, two had 2-h plasma glucose $\geq 11.0$ $\mathrm{mmol} / \mathrm{L}$ and 21 women had fasting plasma glucose levels between 5.1-6.9 $\mathrm{mmol} / \mathrm{L}$ therefore 607 women underwent 1 and 2-hours Oral Glucose Tolerance tests. Of these, 22 and 26 women showed deterioration in glucose tolerance at 1-hr and 2-hr, respectively. Based on the 2013 WHO diagnostic criteria, the prevalence of diabetes in pregnancy was $1.1 \%$ and that of gestational diabetes mellitus was $4.3 \%$ (Table 2 ).
Table 2 Prevalence of gestational diabetes mellitus among pregnant women

\begin{tabular}{|c|c|}
\hline Diagnostic variable & Total, n (\%) \\
\hline \multicolumn{2}{|l|}{ Fasting plasma glucose, $n=612$} \\
\hline$\geq 7.0 \mathrm{mmol} / \mathrm{L}$ & $5(0.8)$ \\
\hline $5.1-6.9 \mathrm{mmol} / \mathrm{L}$ & $21(3.4)$ \\
\hline$<5.1 \mathrm{mmol} / \mathrm{L}$ & $586(95.8)$ \\
\hline \multicolumn{2}{|l|}{ Oral glucose tolerance test, $n=607$} \\
\hline 1-h plasma glucose $\geq 10.0 \mathrm{mmol} / \mathrm{L}$ & $22(3.6)$ \\
\hline 2-h plasma glucose $\geq 11.0 \mathrm{mmol} / \mathrm{L}$ & $2(0.3)$ \\
\hline $\begin{array}{l}\text { 2-h plasma glucose } 8.5-11.0 \\
\mathrm{mmol} / \mathrm{L}\end{array}$ & $26(4.3)$ \\
\hline 2-h plasma glucose $<8.5 \mathrm{mmol} / \mathrm{L}$ & $579(95.4)$ \\
\hline \multicolumn{2}{|l|}{$\begin{array}{l}\text { Overall prevalence of diabetes, } \\
n=612\end{array}$} \\
\hline Gestational diabetes mellitus & $26(4.3)$ \\
\hline Diabetes in pregnancy & $7(1.1)$ \\
\hline No diabetes & $579(94.6)$ \\
\hline
\end{tabular}

Table 3 Logistic regression analysis for factors of gestational diabetes mellitus

\begin{tabular}{|c|c|c|}
\hline Maternal characteristics & $\begin{array}{l}\text { Unadjusted Odds } \\
\text { Ratio }[95 \% \mathrm{CI}]\end{array}$ & P-value \\
\hline \multicolumn{3}{|l|}{ Maternal age } \\
\hline$<35$ & 1.00 & \\
\hline$\geq 35$ years & $1.29(0.55-3.03)$ & 0.56 \\
\hline \multicolumn{3}{|l|}{ Body mass index $\left(\mathrm{kg} / \mathrm{m}^{2}\right)$} \\
\hline $18.5-24.9$ & 1.00 & \\
\hline$\geq 25$ & $22.22(9.39-52.57)$ & $<0.001^{*}$ \\
\hline \multicolumn{3}{|l|}{ Hypertension in Pregnancy } \\
\hline No & 1.00 & \\
\hline Yes & $2.32(0.90-5.99)$ & 0.08 \\
\hline \multicolumn{3}{|c|}{ History of pre-term delivery } \\
\hline No & 1.00 & \\
\hline Yes & $77.17(29.36-202.85)$ & $<0.001^{*}$ \\
\hline \multicolumn{3}{|c|}{ History of spontaneous abortion } \\
\hline No & 1.00 & \\
\hline Yes & $2.12(0.92-4.88)$ & 0.08 \\
\hline \multicolumn{3}{|l|}{ History of stillbirths } \\
\hline No & 1.00 & \\
\hline Yes & $5.67(2.53-12.70)$ & $<0.001^{*}$ \\
\hline \multicolumn{3}{|l|}{ History of macrosomia } \\
\hline No & 1.00 & $<0.001^{*}$ \\
\hline Yes & $98(34.16-283.15)$ & \\
\hline \multicolumn{3}{|l|}{ Alcohol consumption } \\
\hline No & 1.00 & \\
\hline Yes & $4.09(1.75-9.57)$ & $0.001^{*}$ \\
\hline \multicolumn{3}{|c|}{ First degree relative with diabetes mellitus } \\
\hline No & 1.00 & \\
\hline Yes & $8.57(3.53-20.80)$ & $<0.001^{*}$ \\
\hline \multicolumn{3}{|l|}{ Parity } \\
\hline First & 1.00 & \\
\hline Second & $1.15(0.37-3.60)$ & 0.81 \\
\hline Third or more & $1.68(0.59-4.82)$ & 0.33 \\
\hline
\end{tabular}

Note: ${ }^{*}$ The results are significant at $\mathrm{p}<0.05$

The results show that women who are overweight or obese had a 22-fold likelihood of Gestational diabetes mellitus compared to women who had normal or underweight (OR: 22.22, 95\%CI, $9.39-52.57$ ), $\mathrm{p}<0.001$ ); likewise mothers with past history of pre-term delivery were 77-times likely to have GDM compared to those 
without past history of pre-term delivery (OR: 77.17, $95 \% \mathrm{CI}, 29.36-202.85, \mathrm{p}<0.001$ ); and similarly women with first degree relatives with diabetes mellitus had about 9-times likelihood of having GDM compared to those without (OR: 8.57, 95\% CI, $3.53-20.80, \mathrm{p}<0.001$ ). On the contrary, advanced maternal age, being hypertensive during pregnancy, history of spontaneous abortions, and high parity were not associated with gestational diabetes mellitus (Table 3 ).

\section{DISCUSSION}

Using the World Health Organization 2013 diagnostic criteria, we reported a prevalence of gestational diabetes mellitus of $4.2 \%$ among pregnant women living in the southern semi-rural Tanzania. This low prevalence is slightly higher than that of Swai et al in rural Tanzania about three decades ago ${ }^{17}$ but lower than those observed in two previous studies in Tanzania, ${ }^{4,24}$ and other studies in other African countries. ${ }^{18-22}$

Generally, the figure reported in our study is within the reported global range of 3\% to $14 \% .{ }^{27}$ The observed differences in the prevalence rates could partly be explained by the differences in the diagnostic criteria used. Except for studies in South Africa and Tanzania, $, 19,20,24$ most other studies used the 1999 WHO diagnostic criteria.

High maternal BMIs have been previously associated with an increased risk of gestational diabetes mellitus. ${ }^{28,29}$ In their study to estimate risk of gestational diabetes mellitus among women with high pre-pregnancy BMIs, Chu et al. reported unadjusted odds ratios for developing gestational diabetes mellitus were relatively higher in overweight, obese and extremely obese women compared to women with normal BMIs. ${ }^{28}$ Moreover, contrary to our findings, the relative muscle leanness evidenced by normal mean BMI observed among the majority of study subjects $(81.0 \%)$ could explain the low prevalence of gestational diabetes mellitus in this study. The normal mean BMI could also be a result of daily physical activity in the form of housework and farming practised by most women in this study area. An earlier study in Tanzania ${ }^{17}$ attributed the reported zero prevalence of gestational diabetes mellitus to similar factors. Although many years have passed since the study, the traditions of practices and pattern of physical activity of pregnant women in many communities within the country have remained unchanged.

We observed a positive association between having a history of pre-term delivery, stillbirths and macrosomic baby and having a first degree relative with diabetes mellitus with the development of gestational diabetes mellitus.
The findings are consistent with other previous studies. ${ }^{20-}$ ${ }^{24,30}$ A cross-sectional study in Cameroon reported a sixfold increase of gestational diabetes mellitus among pregnant women with a history of unexplained stillbirths (OR: 5.7, 95\%CI: 2.5-12.1), an eightfold increase of gestational diabetes mellitus in women with a history of macrosomia (OR: 8.5, 95\% CI: 3.8-19) ${ }^{31}$ while a study in rural and urban Tanzania showed a 2.8 times elevated risk of gestational diabetes mellitus in pregnant women with past history of stillbirths (OR 2.8, 95\% CI: 1.5-5.4), and a 2.1 times risk of developing gestational diabetes mellitus in women with a positive family history of type 2 diabetes (95\% CI: 1.1-4.2). ${ }^{24}$ Previous studies have also acknowledged obesity and advanced maternal age as risk factors for the development of gestational diabetes mellitus $^{14,15,32}$ while other studies have reported significant associations between gestational diabetes mellitus and parity and history of abortion. ${ }^{15,33}$ On the contrary, our results show advanced maternal age, parity, raised blood pressure during pregnancy and history of abortions were not associated with gestational diabetes mellitus.

Limitations of the study include non-inclusion of prepregnancy BMI as a variable in the assessment of associated factors, instead BMI recorded during the 20 week of gestation was used. Secondly, the study duration of 2 months was too short for this type of study. A longer duration would be required to address risks and maternal or fetal outcomes of the condition. Furthermore, being a cross-sectional study, it was not possible to study the causal relationship of factors and development of GDM. Lastly, the study was done at a single facility, thus findings and conclusions from the study may not be representatiive of the actual prevalence of GDM in the area.

\section{CONCLUSION}

In conclusion, the prevalence of gestational diabetes mellitus was low among rural pregnant women in southern Tanzania.

\section{REFERENCES}

1. Diagnostic criteria and classification of hyperglycaemia first detected in pregnancy. Geneva: World Health Organization; 2013 (WHO/NMH/MND/13.2; Available at http://www.who.int/diabetes/publications/Hypergly caemia_In_Pregnancy/en/

2. Dabelea $\bar{D}$, Snell-Bergeon JK, Hartsfield CL, Bischoff KJ, Hamman RF, McDuffie RS. Increasing prevalence of gestational diabetes mellitus (GDM) over time and by birth cohort - Kaiser permanente 
of Colorado GDM screening program. Diabetes Care 2005;28:579-84.

3. Deierlein AL, Siega-Riz AM, Chantala K, Herring $\mathrm{AH}$. The association between maternal glucose concentration and child BMI at age 3 years. Diabetes Care 2011;34:480-4.

4. Njete HI, John B, Mlay P, Mahande MJ, Msuya SE: Prevalence, predictors and challenges of gestational diabetes mellitus screening among pregnant women in northern Tanzania. Trop Med Int Health. 2018 Feb;23(2):236-42.

5. Gabbe SG, Mestman JH, Freeman RK, Anderson GV, Lowensohn RI. Management and outcome of class A diabetes mellitus. Am J Obstet Gynecol 1977;127:465-469

6. Rich-Edwards JW, Colditz GA, Stampfer MJ, Willett WC, Gillman MW, Hennekens CH, Speizer FE, Manson JE. Birthweight and the risk for type 2 diabetes mellitus in adult women. Ann Intern Med. 1999;130:278-284

7. Shirazian N, Emdadi R, Mahboubi M, Motevallian A, Fazel-Sarjuei Z, Sedighpour N, et al. Screening for gestational diabetes: usefulness of clinical risk factors. Arch Gynecol Obstet. 2009 Dec;280(6):9337.

8. Radesky JS, Oken E, Rifas-Shiman SL, Kleinman KP, Rich-Edwards JW, Gillman MW. Diet during early pregnancy and development of gestational diabetes. Paediatr Perinat Epidemiol. 2008 Jan; 22(1): 47-59.

9. Larijani B, Hossein-nezhad A, Rizvi SW, Munir S, Vassigh AR. Cost analysis of different screening strategies for gestational diabetes mellitus. Endocr Pract. 2003;9:504-9

10. Macaulay S, Dunger DB, Norris SA: Gestational diabetes mellitus in Africa: a systematic review. PLoS One 2014;9(6):e97871.

11. WHO study group on prevention of diabetes mellitus, WHO technical report series No. 844, Geneva, World Health Organization, 1994.

12. Dornhorst A, and Beard RW. Gestational diabetes: a challenge for the future, Diabet Med. 1993;10:897905.

13. Hadden DR. Geographic, ethnic and racial variations in the incidence of gestational diabetes mellitus. Diabetes. 1985 Jun;34 Suppl 2:8-12.

14. Larrabure-Torrealva GT, Martinez S, LuqueFernandez MA, Sanchez SE et al. Prevalence and risk factors of gestational diabetes mellitus: findings from a universal screening feasibility program in Lima, Peru. BMC Pregnancy and Childbirth 2018; 18:303.

15. Jafari-Shobeiri M, Ghojazadeh M, Azami-Aghdash S, Naghavi-Behzad $M$ et al. Prevalence and Risk Factors of Gestational Diabetes in Iran: A
Systematic Review and Meta-Analysis. Iran $J$ Public Health. 2015 Aug;44(8):1036-44.

16. Lutale JK, Justesen A, Swai AB, Alberti KG, Mclarty DF. Glucose-tolerance during and after pregnancy in nondiabetic women in an urbanpopulation in Tanzania. Diabetes Care. 1993 Apr;16(4):575-7.

17. Swai AB, Kitange HM, McLarty DG, Kilima PM, Masuki G, Mtinangi BL, et al. No deterioration of oral glucose tolerance during pregnancy in rural Tanzania. Diabet Med. 1991;8(3):254-257

18. Adendokum AO, Eneli A, KuKu SF: Prevalence of gestational diabetes mellitus in 221 consecutive Nigerian women. Fifth congress pan African diabetes study group. 1995;73.

19. Macaulay S, Ngobeni M, Dunger DB, Norris SA. The prevalence of gestational diabetes mellitus amongst black South African women is a public health concern. Diabetes Res Clin Pract. 2018;139:278-87.

20. Mamabolo RL, Alberts M, Levitt NS, Delemarrevan de Waal HA, Steyn NP. Prevalence of gestational diabetes mellitus and the effect of weight on measures of insulin secretion and insulin resistance in third-trimester pregnant rural women residing in the Central Region of Limpopo Province, South Africa. Diabet Med. 2007 Mar;24(3):233-9.

21. Seyoum B, Kiros K, Haileselase T, Leole A. Prevalence of gestational diabetes mellitus in rural pregnant mothers in northern Ethiopia. Diabetes Res Clin Pract. 1999 Dec;46(3):247-51.

22. Adam S, Rheeder P. Screening for gestational diabetes mellitus in a South African population: Prevalence, comparison of diagnostic criteria and the role of risk factors. S Afr Med J. 2017 May 24;107(6):523-527.

23. Mwanri AW, Kinabo J, Ramaiya K, Feskens EJ. Gestational diabetes mellitus in sub-Saharan Africa: systematic review and meta-regression on prevalence and risk factors. Trop Med Int Health. 2015 Aug;20(8):983-1002.

24. Mwanri AW, Kinabo J, Ramaiya K, Feskens EJ: Prevalence of gestational diabetes mellitus in urban and rural Tanzania. Diabetes Res Clin Pract. 2014 Jan;103(1):71-8.

25. World Health Organization. BMI Classification 2017; Available from: http://apps.who.int/bmi/index.jsp?introPage=intro_ 3.html.

26. World Health Organization. Diagnostic criteria and classification of hyperglycaemia first detected in pregnancy. Geneva: 2013 Contract No.: WHO/NMH/MND/13.2.

27. Benhalima K, Crombrugge PV, Hanssens M, Devlieger R, Verhaeghe J, Mathieu C. Gestational 
diabetes: overview of the new consensus screening strategy and diagnostic criteria. Acta Clin Belg. 2012 Jul-Aug;67(4):255-61.

28. Chu SY, Callaghan WM, Kim SY, Schmid CH, Lau J, England LJ, Dietz PM. Maternal obesity and risk of gestational diabetes mellitus. Diabetes Care 2007 Aug; 30(8):2070-6

29. Torloni MR, Betrán AP, Horta BL, Nakamura MU, Atallah AN, Moron AF, Valente O. Prepregnancy BMI and the risk of gestational diabetes: a systematic review of the literature with metaanalysis. Obes Rev. 2009 Mar; 10(2):194-203

30. Yang X, Hsu-Hage B, Zhang H, Yu L, Dong L, Li J, et al. Gestational diabetes mellitus in women of single gravidity in Tianjin City, China. Diabetes Care. 2002 May;25(5):847-51.

31. Egbe TO, Tsaku ES, Tchounzou R, Ngowe MN. Prevalence and risk factors of gestational diabetes mellitus in a population of pregnant women attending three health facilities in Limbe, Cameroon: a cross-sectional study. Pan Afr Med J. 2018 Nov 20;31:195.

32. Olagbuji BN, Atiba AS, Olofinbiyi BA, Akintayo AA, Awoleke JO, Ade-Ojo IP, et al. Prevalence of and risk factors for gestational diabetes using 1999, 2013 WHO and IADPSG criteria upon implementation of a universal one-step screening and diagnostic strategy in a sub-Saharan African population. Eur J Obstet Gynecol Reprod Biol. 2015 Jun;189:27-32.

33. Waters TP, Dyer AR, Scholtens DM, Dooley SL et al. Maternal and Neonatal Morbidity for Women Who Would Be Added to the Diagnosis of GDM Using IADPSG Criteria: A Secondary Analysis of the Hyperglycemia and Adverse Pregnancy Outcome Study. Diabetes Care. 2016 Dec;39(12):2204-10 